\title{
OBSERVATION OF MESOSPHERIC OZONE AT LOW LATITUDES
}

\author{
P. B. HAYS \\ Departments of Aerospace Engineering, Meteorology and Oceanography, \\ University of Michigan, Ann Arbor, Michigan 48104, U.S.A. \\ and \\ R. G. ROBLE \\ National Center for Atmospheric Research, Boulder, Colorado 80302, U.S.A.
}

(Received in final form 21 August 1972)

\begin{abstract}
Stellar ultraviolet light near $2500 \AA$ is attenuated in the Earth's upper atmosphere due to strong absorption in the Hartley continuum of ozone. The intensity of stars in the Hartley continuum region has been monitored by the University of Wisconsin stellar photometers aboard the OAO-2 satellite during occultation of the star by the Earth's atmosphere. These data have been used to determine the ozone number density profile at the occultation tangent point. The results of approximately 12 stellar occultations, obtained in low latitudes, are presented, giving the nighttime vertical number density profile of ozone in the $60-$ to $100-\mathrm{km}$ region. The nighttime ozone number density has a bulge in its vertical profile with a peak of 1 to $2 \times 10^{8} \mathrm{~cm}^{-3}$ at approximately $83 \mathrm{~km}$ and a minimum near $75 \mathrm{~km}$. The shape of the bulge in the ozone number density profile shows considerable variability with no apparent seasonal or solar cycle change. The ozone profiles obtained during a geomagnetic storm showed little variation at low latitudes.
\end{abstract}

\section{INTRODUCTION}

The first measurement of the ozone concentration in the upper atmosphere was made by Johnson et al. (1951) using u.v. absorption spectroscopy. The ozone number density distribution was determined from the u.v. absorption measurements made at various altitudes by a spectrometer aboard a rocket. Since then daytime measurements of the ozone number density distribution have been made from rockets using the Sun as the u.v. source (Van Allen and Hopfield, 1952; Johnson et al., 1952; L'vova et al., 1964; Poloskov et al., 1966; Nagata et al., 1967; Weeks and Smith, 1968; Krueger, 1969) and nighttime measurements have been made using the Moon as a source of u.v. light (Carver et al., 1967; Carver et al., 1972). The high altitude ozone number density distribution has also been determined from solar occultation measurements made from a satellite (Rawcliffe et al., 1963; Miller and Stewart, 1965). These measurements have determined the ozone number density up to an altitude of about $70 \mathrm{~km}$.

Several other techniques have been used to obtain the ozone number density distribution in the upper atmosphere which include (a) satellite eclipse photometry (Venkateswaren et al., 1961; Fesenkov, 1967), (b) nighttime airglow spectral photometry (Reed, 1968), (c) spectral analysis of backscattered solar radiation as observed from a satellite (Rawcliffe and Elliot, 1966; Anderson et al., 1969), (d) chemi-luminescent ozone sondes (Hilsenrath, 1971) and (e) rocket and ground based observations of the molecular oxygen emission $\mathrm{O}_{2}\left({ }^{1} \Delta g\right.$ ) at $1.27 \mu$ (Evans and Llewellyn, 1970; 1972; Evans et al., 1970). In the latter technique, the ozone number density profile is calculated from the measured altitude profiles of the $\mathrm{O}_{2}\left({ }^{1} \Delta g\right)$ emission at $1 \cdot 27 \mu$ using photochemical theory. Their results give the ozone number density profile at twilight up to $100 \mathrm{~km}$ and preliminary observations indicate a strong seasonal variation of the upper ozone layer at high latitudes. The peak ozone number density at $85 \mathrm{~km}$ varied between $1.3 \times 10^{8} \mathrm{~cm}^{-3}$ in midwinter to less than $0.3 \times 10^{8} \mathrm{~cm}^{-3}$ in midsummer. 
Hays and Roble (1968a) suggested that the nighttime distribution of ozone in the upper mesosphere may be obtained from satellite measurements of the intensity of u.v. stars during occultation by the Earth's atmosphere. During the past few years, we have used the Orbiting Astronomical Observatory (OAO-2) to obtain u.v. stellar occultation data in various spectral regions. The data from the u.v. filters centered at 2390 and $2460 \AA$ have been used to obtain the nighttime ozone number density distribution from 60 to $100 \mathrm{~km}$ at low latitudes. In this paper we describe the experimental technique and present the results which were obtained during quiet and disturbed geomagnetic conditions.

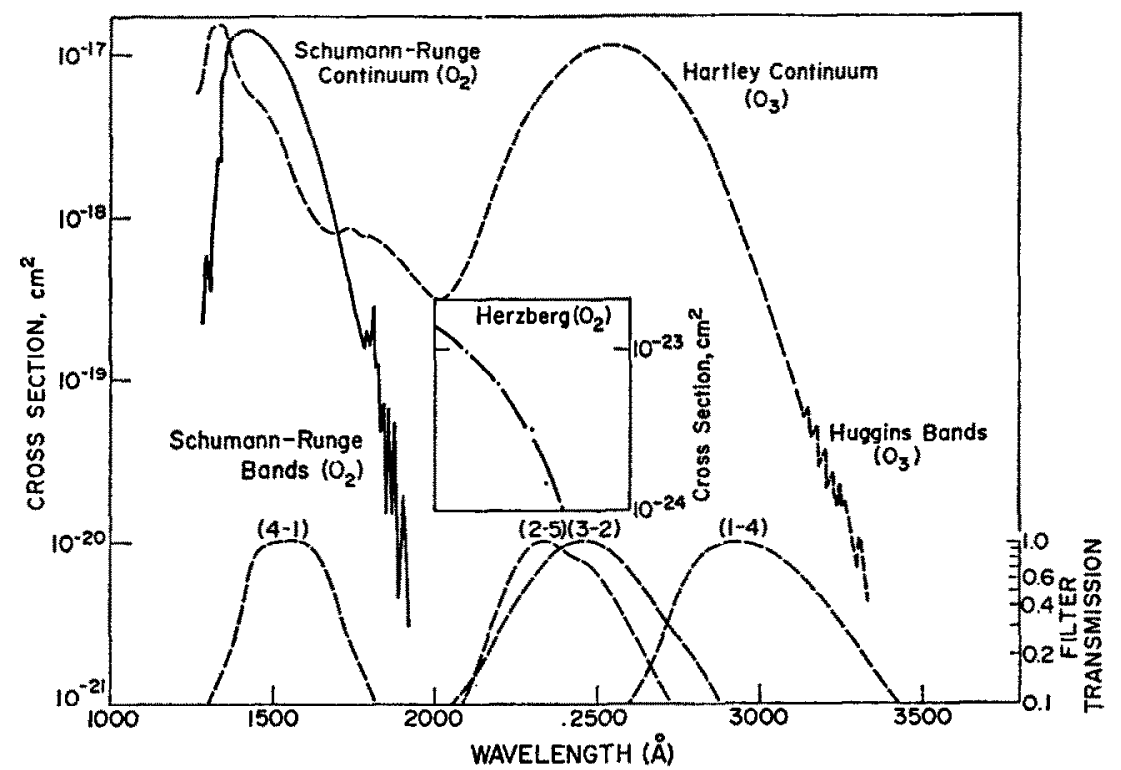

FIG. 1. ABSORPTION CROSS SBCTIONS FOR MOLECULAR OXYGEN AND OZONB IN THB SPECTRAL REGION EXTENDING FROM 1000 TO $3500 \AA$.

Dashed curves are the OAO-2 stellar photometer filter transmission curves used in this study.

\section{EXPERIMENTAL TECHNIQUE}

The general details of the stellar occultation technique have been described by Hays and Roble (1968a, b; 1972), Hays et al. (1972) and Roble and Hays (1972). Here we describe the specifics of the occultation measurements made by the OAO-2 satellite as they apply to the determination of the nighttime ozone number density.

The OAO-2 satellite has one 16 in.-dia u.v. telescope and four 8 in.-dia u.v. telescopes and an u.v. spectrometer having a resolution of approximately $5 \AA$. Filter $2-5$ and 3-2 shown in Fig. 1, are the two filters in the University of Wisconsin optical package that are used for the ozone stellar occultation measurements. The transmission function of these filters is located in the Hartley continuum of ozone (Fig. 1) with the peak transmission at 2380 and $2460 \AA$. The detection systems of the u.v. telescope have a maximum data acquisition rate of $\frac{1}{8} \mathrm{sec}$ time integration resulting in a high altitude resolution at the tangent point. The intensity data are obtained as a function of time, and by knowing the star's position is orbital elements of the satellite, we can relate the intensity to the tangent ray heights during occultation by the Earth's atmosphere. Figure 2 shows the normalized intensity data as a function of tangent ray height for a typical occultation scan. Hays and Roble (1972) describe the technique used to relate the normalized intensity 
data to the tangential column number density of the absorbing species along the ray path. This technique allows for the broadband characteristics of the u.v. transmission function and can be used as long as absorption is due to a single species. Hays and Roble (1968b) have calculated the u.v. transmission of the Earth's upper atmosphere and have shown that the stellar light in the wavelength regions covered by the filter transmission functions, shown in Fig. 1, is primarily absorbed by ozone. However, at

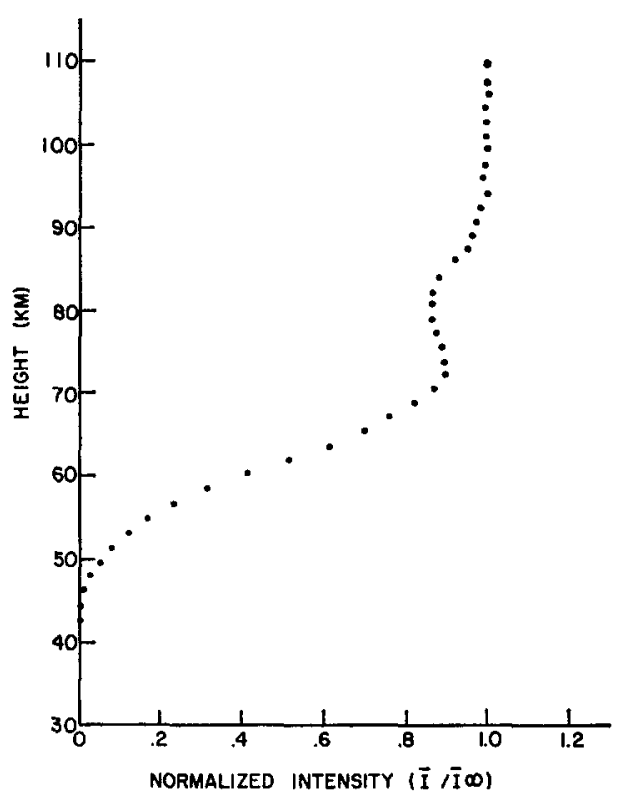

Fig. 2. Normalized intensity Profile for a typical ozone occultation.

altitudes below about $70 \mathrm{~km}$ the stellar ultraviolet light is also absorbed by molecular oxygen in the Herzberg continuum. The absorption contribution in the Herzberg continuum is calculated using the molecular oxygen number density distribution obtained from the CIRA 1965 model atmosphere. This absorption contribution is removed from the stellar intensity data and the corrected normalized intensity is related to the ozone tangential column number density (Hays and Roble, 1972). Once the tangential column number density is known as a function of the tangent ray height, the data are inverted, using the technique described by Roble and Hays (1972), to obtain the local number density at the tangent ray point.

\section{RESULTS}

Stellar occultation measurements using the two filters centered in the Hartley continuum of ozone were made during the period extending from January 1970 through August 1971. From these data we have obtained 12 orbits on which one or both of the filters could be used to determine the ozone density in the mesosphcrc. These results, corrected for molecular oxygen absorption in the Herzberg continuum, and rayleigh scattering are presented in Figs. 3-5 where four separate profiles are illustrated in each figure. According to the analysis of Roble and Hays (1972), the ozone number density is best retrieved from the occultation data between tangent ray heights of 55 to $95 \mathrm{~km}$. The retrieved ozone number density data above and below this altitude interval are less reliable. 

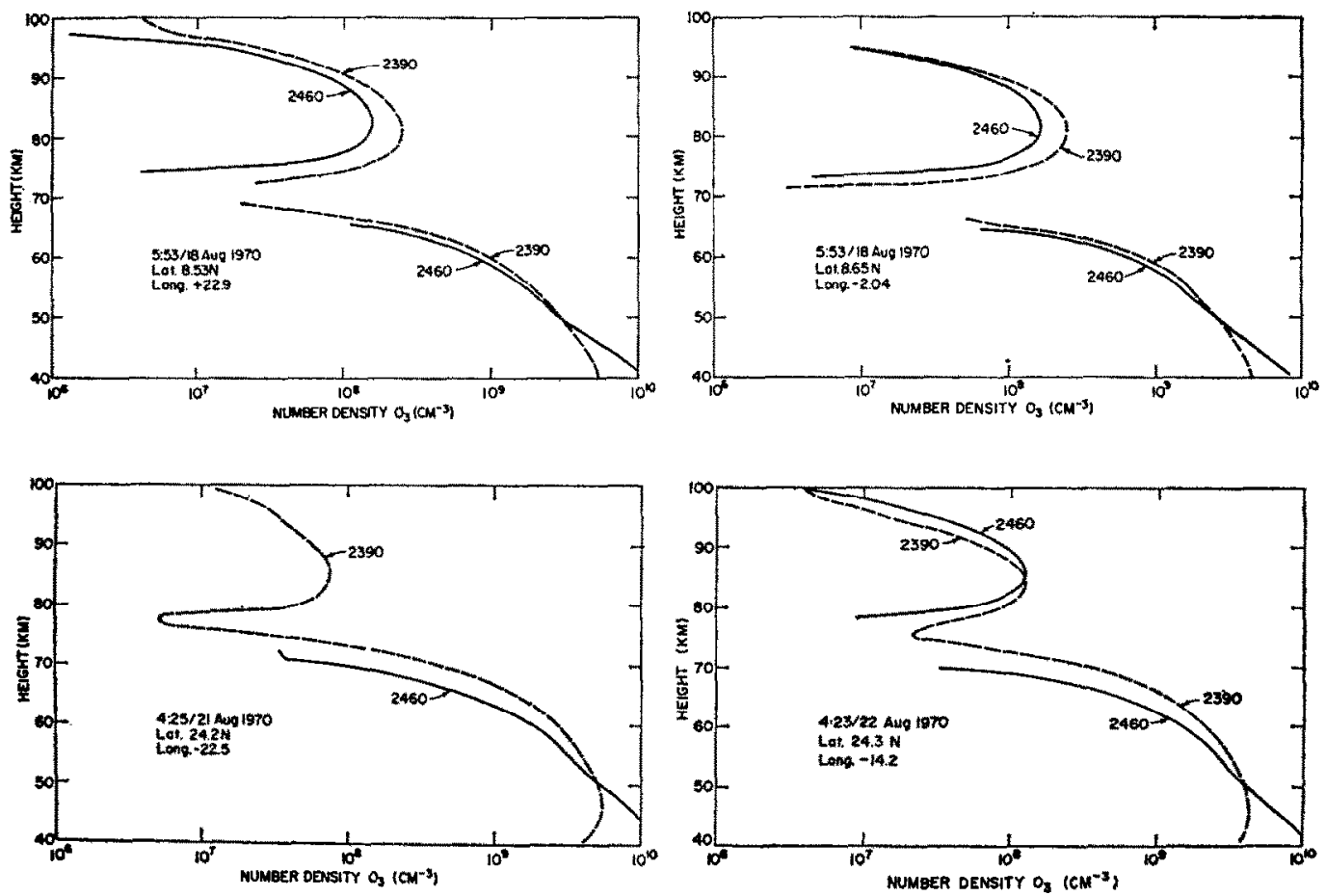

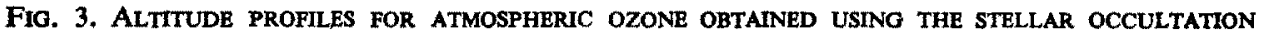
TECHNIQUE.

Geographic position refers to the tangent ray point of the occultation measurements (time as LMT; longitude measured positive eastward from Greenwich).
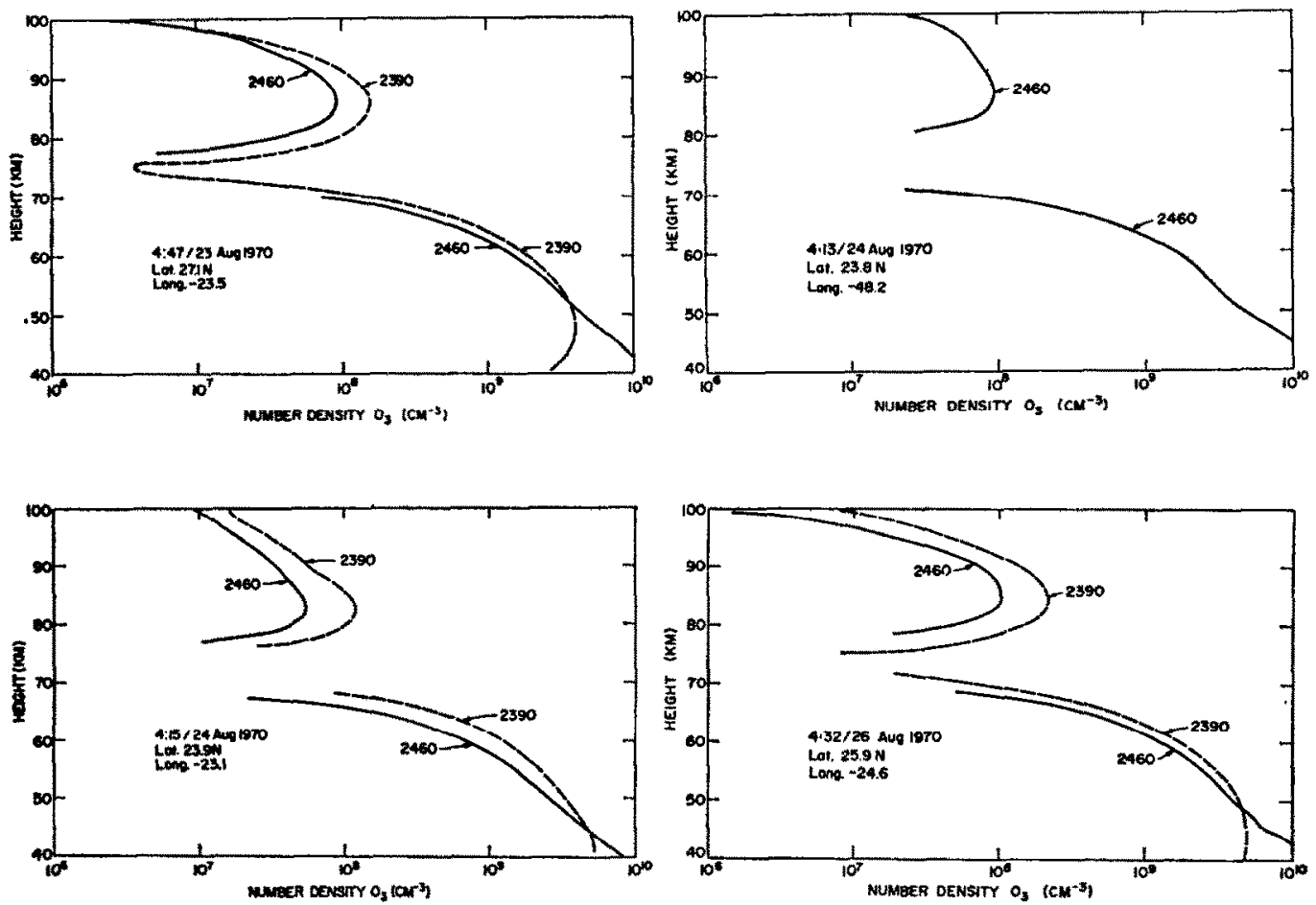

Frg. 4. Same caption as in Fig. 3. 
A careful examination of these ozone profiles in the mesosphere does not show any striking systematic seasonal or diurnal pattern in the equatorial regions. There does appear to be a systematic increase in the altitude of the high altitude ozone bulge with increasing latitude. However, due to the small number of scans, which were made at nearly random local time, season, and latitude, it is difficult to place great weight on the
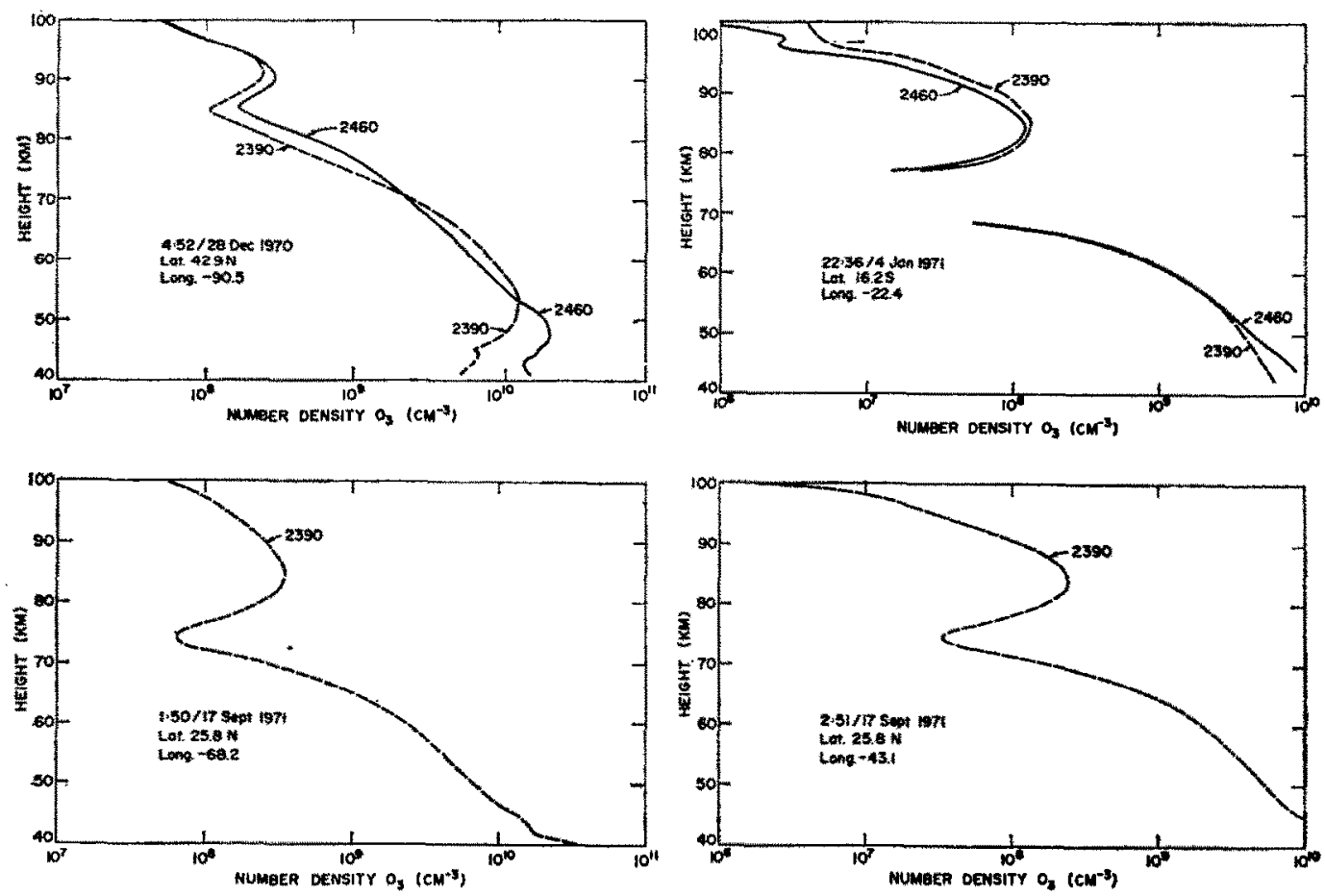

Fig. 5. Same caption as in Fig. 3.

slight variations observed. The major conclusion is that ozone varies very little between 55 and $100 \mathrm{~km}$ during the course of the night at low latitudes. The main feature is the expected bulge in density which occurs at approximately $85 \mathrm{~km}$ and the depletion of ozone just below that altitude. This behavior is predicted by most recent theoretical studies which incorporate the hydrogen chemistry in their model.

Numerous theoretical studies of the chemistry of ozone in a moist atmosphere have followed the early discussion of Bates and Nicolet (1950) of the influence of hydrogen compounds (Hampson, 1964; Hunt, 1966a ; Hunt, 1966b; Hesstvedt, 1968; Leovy, 1969; Bowman et al., 1970; Hunt, 1971; Shimazaki and Laird, 1972; Strobel, 1972). The result of these studies is somewhat confusing due to the large number of choices of possible rate coefficients, photodissociation rates, boundary conditions, and eddy mixing rates used by these authors. The theoretical results do indicate the general features observed in the OAO-2-A2 stellar occultation measurement. This is illustrated in Fig. 6 where three representative theoretical profiles (Hesstvedt, 1968; Shimazaki and Laird, 1970; Hunt, 1971) are compared with our envelope curve. Hunt (1971) appears to agree best with the observations, but it is difficult to assess whether this is fortuitous or the result of a correct choice of the multitude of possible variable factors. 


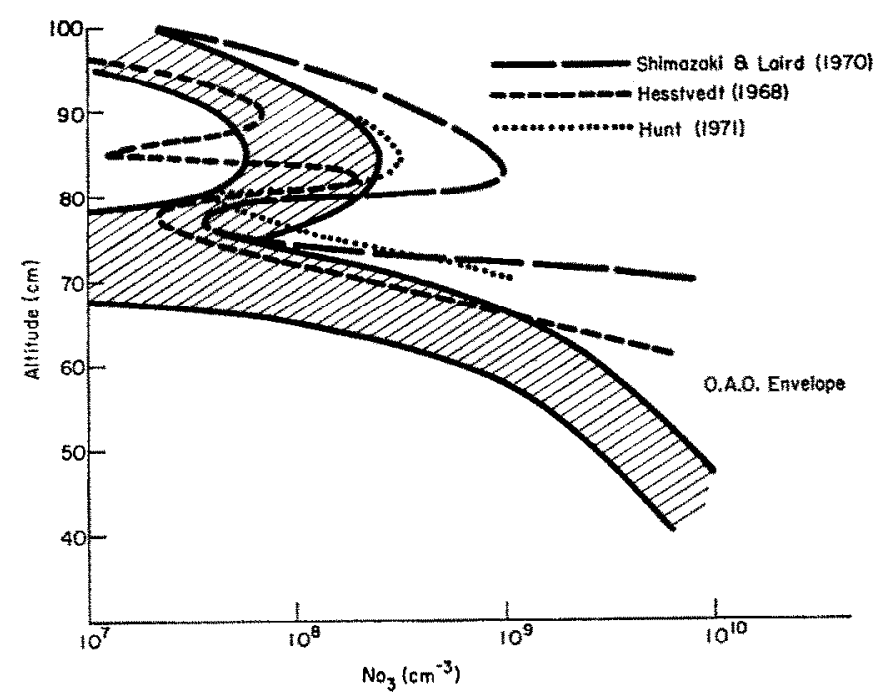

Fig 6. Comparison of measured ozone envelope with theoretical calculations.

It should be pointed out that during the period of time in which these observations were taken one series of measurements was made while the large magnetic storm of August 1970 was in progress. There does not appear to be any significant correlation between the ozone density in the mesosphere and storm in agreement with the prediction of Maeda and Aiken (1968). This is not surprising, but relatively large variation in $\mathrm{O}_{2}$ at higher altitudes was observed (Hays and Roble, 1972) at the same time.

\section{SUMMARY}

The stellar occultation measurements of ozone in the mesosphere indicate the following conclusions:

1. Mesospheric ozone varies by as much as a factor of 4 at high altitudes, but does not show any clear seasonal or diurnal nighttime pattern. A slight increase in the altitude of the $85 \mathrm{~km}$ bulge appears to be associated with increasing latitude.

2. The observations are generally in agreement with results of theoretical predictions which utilize a moist atmosphere in which hydrogen compounds are considered in the chemistry.

3. There is no apparent relationship between mesospheric ozone and geomagnetic activity at low latitudes.

Acknowledgement-This work was supported by NASA Grant NGR 23 005-360 and NASA Contract NAS 1 9958. The National Center for Atmospheric Research is sponsored by the National Science Foundation. We wish to acknowledge the helpful support of Dr. Houk, and the O.A.O. Wisconsin and NASA experimental team.

\section{REFERENCES}

Anderson, G. P., Barth, C. A., CAYla, F. and London, J. (1969). Satellite observations of the vertical ozone distribution in the upper atmosphere. Annls Géophys. 25, 341.

Bates, D. R. and NrCOLET, M. (1950). The photochemistry of atmospheric water vapor, $J$.geophys. Res. 55, 301.

Bowman, M. R., Thomas, L. and Geisler, J. E. (1970). The effect of diffusion processes on the hydrogen and oxygen constituents in the mesosphere and lower thermosphere. J. atmos. terr. Phys. 32, 1661.

Carver, J. H., Horton, B. H. and Burger, F. G. (1967). Rocket determination of the night ozone distribution and the lunar ultraviolet flux. Space Research VII, p. 1020. 
Carver, J. H., Horton, B. H., O'Brien, R. S. and RoFe, B. (1972). Ozone determinations by lunar rocket photometry. Planet. Space Sci. 20, 217.

EvaNs, W. F. J., WOOD, H. C. and LLEWELLYN, E. J (1970). Ground-based photometric observations of the $1.27 \mu$ band in the evening twilight. Planet. Space Sci. 18, 1065.

Evans, W. F. J. and Llewrelyn, E. J. (1970). Molecular oxygen emissions in the airglow. Annls Geophys. 26, 167

Evans, W. F. J. and Llewellyn, E. J. (1972). Measurements of mesospheric ozone from observations of the $1.27 \mu$ band. Radio Sci. 7, 45 .

FesenKov, V. G. (1967). A satellite technique for sounding the optical properties of the atmosphere. Soviet Astron. AJ, 11, 1.

HAMpson, J. (1964). Photochemical behavior of the ozone layer. Can. Armament Res. Develop. Estab. Tech. Note 1627/64 Carde, Quebec, Canada.

HAYS, P. B. and RoBle, R. G (1968a). Atmospheric properties from the inversion of planetary occultation data. Planet. Space Sci. 16, 1197.

HAYS, P. B. and ROBLE, R. G. (1968b). Stellar spectra and atmospheric composition. J. atmos. Sci. 25, 1141 .

HAYs, P. B., RoBle, R. G. and SHAH, A. N. (1972). Terrestrial atmospheric composition from stellar occultations. Science, 176, 793.

HAYs, P. B. and ROBLE, R. G. (1972). Stellar occultation measurements of molecular oxygen in the lower thermosphere. Planet. Space Sci. In press.

HEsstvedT, E. (1968). On the effect of vertical eddy transport on atmospheric composition in the mesosphere and lower thermosphere. Geophys. Norv. 27, 1.

HiLSENRATH, E. (1971). Ozone measurements in the mesosphere and stratosphere during two significant geophysical events. J. atmos. Sci. 28, 295.

HUNT, B. G. (1966a) The need for a modified photochemical theory of the ozonosphere. J. atmos. Sci. $23,88$.

HuNT, B. G. (1966b). Photochemistry of ozone in a moist atmosphere. J. geophys. Res. 71, 1385.

Hunt, B. G. (1971). A diffusion photochemical study of the mesosphere and lower thermosphere and the associated conservation mechanism. J. atmos. terr. Phys. 33, 1869.

Johnson, F. S., PuRCELl, J. D. and TOUSEY, R. (1951). Measurements of the vertical distribution of atmospheric ozone from rockets. J. geophys. Res. 56, 583.

Johnson, F. S. Purcell, J. D., Tousey, R. and Watanabe, K. (1952). Direct measurements of the vertical distribution of atmospheric ozone to $70 \mathrm{~km}$ altitude. J. geophys. Res. 57, 157.

KRUEGER, A. J. (1969). Rocket measurements of ozone over Hawaii Annls Géophys. 25, 307.

LEOVY, C. B. (1969). Atmospheric ozone: An analytic model for photochemistry in the presence of water vapor. J. geophys. Res. 74, 417.

L'vovA, A. A., Mrkrov, A. Y. E. and Poloskov, S. M. (1964). Rocket investigation of the vertical ozone distribution above the level of maximum concentration during the total solar eclipse of February 15, 1961 . Geomagn. Aeron. 4, 839.

MAEDA, K. and AIKEN, A. C. (1968). Variations of polar mesospheric oxygen and ozone during auroral events. Planet. Space Sci. 16, 371.

Miller, D. E. and StewarT, K. H. (1965). Observations of atmospheric ozone from an artificial earth satellite. Proc. $R$. Soc. A288, 540.

Nagata, T., Tohmatsu, T. and Tsuruta, H. (1967). Observations of mesospheric ozone density in Japan. Space Research VII, p. 639.

Poloskov, S. M., Lvova, A. A. and Mixirov, A. E. (1966). Rocket measurements of ozone profiles above the level of maximum concentration. Space Research VII, p. 1009.

Rawcliffe, R. D., Meloy, G. E., Friedman, R. M. and Rogers, E. H. (1963). Measurement of vertical distribution ozone from a polar orbiting satellite. J. geophys. Res. 68, 6425.

RAWCLIFFe, R. D. and Elulor, D. D. (1966). Latitude measurement of ozone at high altitude deduced from a satellite measurement of the earth's radiance at $2840 \AA$. J. geophys. Res. 71, 5077.

REED, E. I. (1968). A night measurement of mesospheric ozone by observations of ultraviolet airglow. J. geophys. Res. 73, 2951.

RoBLe, R. G. and HAYs, P. B. (1972). A technique for recovering the vertical number density profile of atmospheric gases from planetary occultation data. Planet. Space Sci. 20, 1727.

SHIMAZAKI, T. and LAIRD, A. R. (1972). Seasonal effects on distributions of minor neutral constituents in the mesosphere and lower thermosphere. Radio Sci. 7, 23.

STRobel, D. F. (1972). Minor neutral constituents in the mesosphere and lower thermosphere. Radio Sci. $7,1$.

VAN Allen, J. A. and Hopfield, J. J. (1952). Preliminary report on atmospheric ozone measurements from rockets. Mem Soc. R. Sci., Liege 12, 179.

Venkateswaran, S. V., MOORE, J. G. and KRUEGER, A. J. (1961). Determination of the distribution of ozone by satellite photometry. J. geophys. Res. 66, 1751 .

WeEKs, L. H. and SMrTH, L. G. (1968). A rocket measurement of ozone near sunrise. Planet. Space Sci. $16,1189$. 